\title{
Technologies of treatment: scaling up ART in the Western Cape, South Africa
}

Fareed Abdullah and Corinne Squire

\section{Introduction}

This chapter examines technologies of 'treatment scaleup,' the extension of antiretroviral treatment (ART) to most or all of HIV positive people who need it, in the Western Cape, South Africa. The chapter describes three technologies related to ART scaleup: those of administration; partnership, rather different to the 'partnership' Campbell (this volume) describes and thirdly what we refer to as treatment citizenship. These non-medical treatment technologies operate alongside conventional medical treatment technologies to make up a successful, even exemplary ART scaleup. The chapter also argues that the success of these technologies derives from their involvement in a larger phenomenon: a new construction of 'HIV citizenship' within the Western Cape.

The Western Cape's ART programme, begun in April 2004, was the first treatment scaleup to high levels of provision within a high-prevalence low-resourced context. At the time, many politicians, policymakers and clinicians thought that delivering ART programmes in such settings was dangerous or impossible. Today, the programme's success and influence, particularly for other developing-world scaleup programmes, is widely acknowledged (World Health Organisation, 2007). The Western Cape's earlier 59 
demonstration projects, starting in 2001 in the township of Khayelitsha, near Cape Town (Coetzee et al., 2004), were important models for the World Health Organisation (WHO)'s ' 3 by 5' programme, aiming to provide ART to 3 million HIV positive people by 2005 - a goal met two years late (see http://www.who.int/mediacentre/factsheets/2003/fs274/en/ and World Health Organisation, 2006). The first author of this chapter headed Western Cape AIDS programmes from 1996 to 2005, and directed the scaleup (Abdullah, 2004, 2006; Abdullah et al., 2006; Boulle et al., 2008). He now works with the Global Fund to Fight AIDS, Tuberculosis and Malaria, as Africa Unit Director, again with scaleup a priority. The second author conducted interviews about HIV support with HIV positive people in the Western Cape between 2001-4, when many interviewees were beginning or contemplating ART (Squire, 2007). This chapter draws predominantly on the first and to a lesser extent on the second area of work.

How did particular technologies deliver the Western Cape scaleup? This chapter takes technologies to be "hybrid assemblages" (Rose, 2007: 17) of knowledges, practices and material resources that have particular effects. In this case, they are directed at enabling people with HIV-related illness to be healthy, happy and socially active. The 'hybrid' diversity of the administrative, partnership and treatment citizenship technologies examined here renders them heterogeneous; they intersect with and sometimes contradict each other. And power does not lie only with the technologies' makers and controllers. Their natures, applications and ownership are contested by everyone involved with them. 60 
Administrative technologies are rarely examined in accounts of HIV treatment. Lacking clear or appealing politics, they usually appear simply as bureaucracy. However, they can have important political effects, as well as treatment effectiveness, depending on how their ownership is structured. In this chapter, they counter the instances Campbell describes of determining and surveillant, top-down bureaucratisation. Partnership technologies, often present solely in the discourse of the more powerful partners, can also be to some extent delivered in practice - as Campbell's chapter demonstrates, and this chapter reiterates. What we are calling 'treatment citizenship' technology is harder to describe, lying in the fields of education, social dialogue and community action. Elements of it are however frequently identified as contributing to the success of HIV programmes. In the Western Cape scaleup, treatment citizenship's effectiveness is very clear.

The chapter suggests that that these technologies worked within a larger frame of developing discourses and practices of 'HIV citizenship'. This concept has some important precedents. Rabinow (1996) describes a 'biosocial' realm of collectively articulated experience and organisation, through which human subjects engage critically and sometimes effectively with discourses of post-nineteenth century biopower (Foucault, 1980). Rose (2007: 134) frames this "collectivising moment" as one aspect of 'biological citizenship.' Such citizenship, constituted by individualising biopower, allows some space for subjects to wrest some power for themselves, individually and collectively, on the basis of their 'vital interests'. Rose cites HIV activism as an example of biological 61 
citizenship; others include genetic citizenship, bioinformational citizenship, and biopolitical citizenship generally, a category into which HIV activism may fall.Robins (2008) frames South African HIV activism as 'health citizenship', a description that attends both to the country's radical constitutional guarantee of healthcare for all, and to the necessarily integrated nature of healthcare activism in developing-world contexts, where access to all medical care, not just ART, is restricted, and where health is undermined by hunger and poor infrastructure as well as disease. Robins focuses on HIV activists, for whom making connections between HIV and other issues is central to political effectiveness. Our concern with the Western Cape ART programme, however, takes in the whole of the province's HIV positive population, even those with little connections to non-medical services; addresses the specificities of HIV treatment needs and makes attention to $H I V$ citizenship more appropriate.

Citizenship for an HIV-infected or affected person has to be constructed in relation to the particularities of HIV: its fatal or, since the mid-1990s, potentially chronic character; its stigmatisation and associations with socially 'transgressive' sexualities and drug use; its national significance in high-prevalence countries, particularly in sub-saharan Africa and its global politics which imbricates all HIV positive people in transnational as well as local debates. These specific characteristics, as well as the more general health and biological components of HIV citizenship, shape HIV technologies like those driving the Western Cape's scaleup. 
Despite the success of the Western Cape programme, problems remain. There are difficulties of sustainability, accountability and democracy in the programme's systems, as well as in its local, national and international governance. Treatment does not work for everyone; has sideeffects and may need to change periodically. It also produces fresh challenges in people's lives as HIV becomes a long-term but still-stigmatised and potentially fatal illness, with new implications for employment, family roles and sexual relationships. In epidemics where prevalence and incidence (annual new cases) remain high, as in South Africa, the economic future of ART is hard to guarantee without factoring in effective prevention; treatment's relation to prevention is also much debated. Universal ART can have resource-diverting implications for other public services, particularly health, and for the voluntary sector. The successful scaleup technologies and discourses and practices of HIV citizenship described in this chapter do not circumvent the problems of 'development' Campbell adumbrates when discussing 'partnership' and 'capacity building'. Western Cape scaleup experiences also indicate that novel 'psychosocial' issues continually arise. Nevertheless, this chapter suggests that the Western Cape scaleup demonstrates the possibility of treatment technologies operating effectively in high-prevalence, low-resource contexts, as part of broader formations of HIV citizenship, pragmatically aligning effectiveness with medical and political hope.

The next sections of the chapter describe the context and nature of the scaleup, before examining the three technologies, and their current and future limitations 


\section{Anti-retroviral treatment: A ‘universal' technology?}

One of the UN Millenium Development Goals is to "combat HIV/AIDS, malaria and other diseases" and halt HIV's spread by 2015 (http://www.un.org/millenniumgoals/). The UN, G8 and African Union pledge treatment and care for HIV to $80 \%$ of those who need it, and $25 \%$ reductions in HIV prevalence, by 2010. Three million people are now thought to be taking ART (World Health Organisation, 2008), the most effective medical treatment for people with serious HIV illness - up from 400000 in 2003 (World Health Organisation, 2006). This medical treatment technology has powerful consequences, markedly decreasing HIV mortality and prolonging life. In the developed world, many HIV positive people are now living in their second decade of treatment. When treatment is generally available, people access it when they are healthier and more likely to do well (Boulle et al., 2008). When HIV positive people on ART have unsafe sex, there is less likelihood of them transmitting HIV. When HIV positive women on ART have children, those children are less likely to have HIV (Jackson et al., 2007). Expanded treatment also reduces the pandemic's psychosocial, economic and political effects - especially significant for high-prevalence epidemics in subsaharan Africa. By turning HIV from a fatal condition into a manageable, if difficult, chronic illness, ART reduces stigma (Wolfe et al., 2008) and enables disclosure (Skogmar et al., 2006) and this in turn encourages testing, and others' early, successful treatment (Chesney and Smith, 1999). ART means less strain on health services, more people working, more parents looking after children, fewer orphans. It ameliorates the lives of some of the most disadvantaged people in the world. Its absence, and communities' resulting decimation by HIV, can lead to powerful 
social and political disaffection.

'Universal' ART provision is hard to attain. It is economically, institutionally and socially difficult to implement, and the pandemic, the virus, and treatment itself are uncertain and changing . ART is prohibitively expensive, particularly those second-line and later variants not available as generics, for high-prevalence low- and middle-income countries. These countries are therefore positioned as perpetual aid recipients, sourcing a significant share of ART's cost from international donors such as PEPFAR and the Global Fund. As epidemics 'mature' and more people get ill, as new infection rates remain high, as HIV diverts or is perceived to divert resources from additional important health and other basic needs and as international NGOs backpedal on or struggle to meet - depending on your perspective - their universal treatment commitments, ART's sustainability is often questioned. ART is also said to be potentially enabling transmission by presenting HIV as a manageable chronic illness, untransmissible when treated (Davis, this volume), turning it into a medicalised, technologically-determined condition, and obviating HIV prevention, without which the possibility of universal treatment recedes further.

An early objection to universalising treatment in developing-world epidemics was that complicated medications could not work for resource-deprived people, adherence would be poor and resistance would grow. However, adherence is higher in developing- than developed-world epidemics, and adherence-related resistance is low (Boulle et al., 2008). Another objection is that 'gold-standard' ART treatment programmes, medically on par 65 
with the developed world and providing 'wraparound' social services, are divisive resource misuse. As Lee (2006), head of the ' 3 by 5' programme, notes against this westcentred criticism, such programmes are not viewed as over-provision in their own context. Similarly, the organisation Partners for Health, responsible for innovative HIV treatment in Haiti and Malawi, opposes dual-track care, suggesting treatment "should be both medical and moral...based on solidarity, rather than charity alone", involving "everything that the providers would do for their families - or themselves" (http://www.pih.org/who/vision.html).

Do the difficulties of universal treatment mean that there will continue to be 'us' and 'them' HIV epidemics, distinguished by ART access and its lack? This chapter argues that we are living neither with two treatment-differentiated epidemics, nor in the 'postcrisis' situation described in some developed-world communities with treatment access (Rofes, 1998) but rather in a stage characterised by universalised HIV knowledge, including treatment knowledge, but uneven provision and expectations. This is still a 'treatment possibility' rather than a 'treatment' era. This stage nevertheless raises some common debates across the diversity of national epidemics, about how ART technologies, as well as HIV care, education and support technologies, are working, and how they could operate better.

\section{Scaling up ART in a high HIV-prevalence province}

South African addresses to treatment technologies are instructive to consider since the 66 
country has high prevalence - $16 \%$ among adults (UNAIDS, 2008) - and more people on treatment than any other nation. Despite great economic diversity, South Africa is a middle-income nation, with relatively well-developed health services and infrastructure in urban and periurban areas. Today, between $28 \%$ and $42 \%$ of the approximately 900000 people estimated to need treatment, are receiving it (World Health Organisation, 2008; Republic of South Africa, 2008). In 2004, when the Western Cape province's ART scaleup began, there were no government plans to provide ART. In a reconstructing country faced with five million people dying from HIV-related illnesses within a decade, and with relatively good internal and external resources, treatment seemed to many both an ethical necessity and an economic and practical possibility.

In 2004, the Western Cape decided to make ART, previously restricted to a small number of sites, available to all the people in the province who needed it. Currently around twothirds of those thought to need ART in the province, are taking it. On conservative calculations, $72 \%$ of the first adult and $85 \%$ of the first child patients, many of whom started treatment when very sick and who came from a highly mobile periurban population, are still in the programme (Boulle et al., 2008). Life expectancy when they started was at most one year.

At the beginning of scaleup, Western Cape HIV prevalence in the Western Cape was estimated at $200000-300000$ out of a $4.2 \mathrm{~m}$ population (http://www.capegateway.gov.za/eng/your_gov/305). 10-20\% needed ART according to 67 
WHO guidelines on treatment. HIV affects fewer people, proportionally (13\%, from antenatal screening) and in absolute numbers, than in other South African provinces, because of the population's higher socioeconomic status and because the most HIVaffected, black-African community in South Africa constitutes a relatively small fraction of the Western Cape population. However, antenatal prevalence in some districts reaches $33 \%$. The province's resources, better overall than those of others, are low in rural areas, posing considerable scaleup challenges in some heavily-affected districts. The health service suffers chronic understaffing, poor management and organisation, and lack of computerisation. There are eight million visits per year to clinics and four million visits per year to community health centres (Abdullah et al., 2006); by 2010, 25\% will be for HIV (Abdullah, 2004).

Demonstration ART programmes at innovator sites had early success in the province in 2001 (Coetzee et al., 2004), building on the succcess of Prevention of Mother-To-Child Transmission, or PMTCT, programmes which the provincial health department had begun in 1998. After court action by activists against the government, who said it would be unworkable and too expensive, these successful, cheap and popular PMTCT programmes rolled out nationwide, albeit slowly, from 2001 (Moodley et al., 2003); but PMTCT was accessible throughout the Western Cape by 2003. Currently, Western Cape transmission rates for HIV positive women are 6.1\% (Draper et al., 2007). The province's early-adopted and rolled-out PMTCT programmes formed an important treatment literacy foundation for patients and staff, particularly in the early stages of the ART scaleup. 
By April 2004, when the national ART plan was implemented, the Western Cape already had 16 ART sites, treating 2327 people with Stage IV HIV illness or CD4 counts below 200/ $\mathrm{mm}^{3}$ - a fourfold increase over the previous six months (Coetzee et al, 2004;

Western Cape Department of Health, 2006). The province then rolled out ART to all major towns at 43 sites, two-thirds in primary care settings. 7-10,000 people died in 2005 without accessing ART, but by March 2006, numbers had reached 16234 adult and child patients on treatment - 65\% coverage for both groups (Boulle et al., 2008). Figures for 2008 doubled, at 37500 (Uys, 2008).

Criteria for success in the Western Cape ART programme are high levels of patients retained in care, and high levels of viral suppression amongst those patients. At the end of scaleup patients' first year on treatment, $75 \%$ had a CD4 count above 200 cells $/ \mathrm{mm}^{3}$. This figure increased to $86 \%$ at two years and $95 \%$ at four years on ART. Viral load tests showed $88 \%$ of adult patients achieving virological suppression after a year on ART and $85 \%$ showing suppression after 4 years. In this treatment-naïve population, virological suppression could be expected; but the rate is still very good in comparison with other rich and developing countries. Deaths in the first six months of treatment are now half what they were initially, as less-ill people seek treatment. $17 \%$ of patients are on second line therapy after four years (Boulle et al., 2008).

ART's expansion and success in the Western Cape demonstrate ART scale-up's 69 
feasibility in resource-constrained settings. The scale-up started in a situation of low national HIV resourcing and education, relatively low levels of local health and social resources; low government commitment, patchy international commitment, pre-Global Fund, and the numerically largest national epidemic, with still-increasing incidence. In such circumstances, scaleup success merits attention. How did it happen?

In the Western Cape programme, pre-ART care for people living with HIV is provided mainly at local clinics and comes predominantly from nurses, who conduct voluntary counselling and testing, provide care for minor ailments, give ongoing counselling, and are responsible for regular checkups including six-monthly CD4 counts. Community health centres or district hospital outpatient departments initiate and maintain ART. HIV services, particularly ART programmes, always work with local NGOs and communitybased organisations (CBOs). How this occurs, depends on agreements between specific health facilities and the organisations. These agreements involve HIV prevention and education NGOs and CBOs, as well as those focusing on ART literacy and support, and NGOs and CBOs with other remits such as counselling, advocacy, income generation, homecare and childcare. ART clinics, support services and PMTCT programmes are located close together, usually in the same building. ART delivery is always accompanied by education and counselling or peer support. It includes encouragement to disclose to at least one person in the patient's home environment. Again, its specific nature is determined by clinicians and NGOs or CBOS, but the programme emphasises 'psychosocial' factors such as understanding and accepting HIV status; 'positive' ways of 70 
living with HIV in sexual relationships, in having children, and in nutrition, exercise and drug and alcohol consumption; and family and friendship network disclosure and support. There are strict protocols for patient recruitment, medication, and monitoring ART and other health progress, sometimes exceeding WHO guidelines. There is a firmlyguaranteed supply of ART drugs, not easy where ART provision depends significantly on international donors. There is good additional care - secondary referrals for TB, immune reconstitution disease, and major side-effects - which enables good adherence. There are special arrangements for children, and for patients who are pregnant or who have psychiatric issues. Partnerships with national and international NGOs are actively pursued (Abdullah, 2004).

\section{Political technologies of scaleup}

We might expect, from South Africa's political contests around HIV and the country's politicised recent history, that ART scaleup would involve political technologies: explicit contests over power relations. However, as the above description indicates, there were no explicit political alignments within the programme. Political commitment from national leaders, is often declared critical in tackling HIV epidemics, as in Uganda and Botswana (Epstein, 2006). In 2004, South Africa's governing ANC exhibited considerable disengagement from HIV. The Western Cape's political unpopularity at national level, because of its privilege and conservatism and the ANC's weaker position there, paradoxically enabled provincial support of ART scaleup and even of treatment HIV activism such as that of the Treatment Action Campaign (TAC). Later, as national health 71 
policy shifted towards ART scaleup, the Western Cape gained the position, highly unusual for this province, of national exemplar.

It might seem likely that the Western Cape scaleup's success drew on grass-roots traditions of political activism derived from the anti-apartheid struggle. This link is, though, hard to substantiate. Some NGO, CBO and health service workers and volunteers involved in the scaleup had participated in 1980s United Democratic Front campaigns, and in lesbian and gay activism; most had no such histories. Moreover, many of the health and social service professionals, civil servants, politicians, advocates and activists involved were too young for their efforts to be understood as a direct legacy of antiapartheid struggle. The indirect legacy of this struggle for South Africa's HIV campaigns is indeed significant (Robins, 2008). It is possible, too, that the Truth and Reconciliation Commission's high-profile disclosures enabled HIV activism in the Western Cape's relatively politically open context. However, the context of the Western Cape scaleup, these legacies were only part of a multi-level technological network.

\section{Administrative technologies of scaleup}

The technologies of the scaleup can be understood as first of all administrative rather than political govermentality. The scaleup's managerial sophistication has often been noted as distinguishing it from other provinces' programmes (Abdullah, 2004; Beresford, 2004). Administration acted as a kind of politics in itself, counteracting the simplifications and paralyses produced by 'politics-first' approaches to the pandemic demonstrated well in 
Campbell (this volume). Like conventional political technologies, this administrative technology involved decision-making and promoting change. Administration - a term derived from a word for 'service' - became, in the scaleup, a patient-centred, patientserving political strategy.

The scale-up was planned by health department officials in consultation with clinicians and international, national and local NGOs. In addition to following WHO protocols and providing referrals for difficult issues, the health department asked clinics to develop broad psychosocial guidelines across all aspects of the programme. For instance, some selection guidelines addressed clinic attendance, successful TB treatment, treatment literacy, and substance abuse issues. Support guidelines focused on adherence issues, but also less immediately relevant concerns such as relationships. The structure and content of psychosocial support does not seem to have affected ART outcomes, but support perceived as well-administered was judged to perform best (Infectious Disease Epidemiology Unit/Department of Health, 2006).

The province put special effort into working with pharmacological services on drug sourcing and distribution. Previous province health initiatives had not addressed these services, but they were key for a programme depending on a rapid increase, provincewide, in drug availability; on imported drugs involving complex ordering and processing; on low-supply, high-demand drugs liable to 'leak' from the system and on a treatment protocol opposed by government and therefore liable to experience national-level 73 
administrative delays. The province also instituted programme-wide 'basics first' monitoring of patient retention, progress, amount and rate of antiretroviral drugs used, and - via treatment waiting time guidelines - care quality. This thorough and painstaking monitoring required already hard-worked professionals to keep additional detailed handwritten records. More complex data were collected from 'sentinel' sites with electronic access (Boulle et al., 2008; Western Cape, 2007). The data were powerful ripostes to arguments about the impossibility of making ART treatment work in generalised high-prevalence low-resource epidemics. Some procedures and data turned out to be unnecessarily cautious and detailed. Adherence and loss to followup, addressed and defined more strictly than in developed-world programmes, proved less than expected, and viral rebound rates have not been high (Boulle et al., 2008). However, such 'overadministration' was a highly effective strategy, rendering the programme politically impregnable and building commitment to and confidence in it among patients and staff.

The politics of biocapital (Sunder, 2006), an economic form dedicated to extracting surplus financial and epistemic value from the 'vital' properties of living organisms (Rose, 2007), tends towards the minimum, quickest-achievable standards of administrative care, that will substantiate the value rather than the shortcomings of biological science. The administrative technology of this biocapital rollout was by contrast highly cautious and regulatory. It shared, however, one common characteristic of biocapital development: rapidity. 
Speed was important to reach people in this escalating epidemic; to try to reduce transmission through education and lower infectivity by treatment; to get treatment to people when they were at manageable numbers and before it was too late for them and to establish treatment structures for the larger numbers who would need them later. To achieve this, the programme's management structures had to be rapidly effective. From the beginning, they had to provide drugs consistently, and to sustain an infrastructure that would let drugs be prescribed and taken effectively, encouraging adherence and minimising the development of resistance. Speed was promoted by putting policy and planning targets into the annual budget: the budget itself became a scaleup tool. Often this involved informed approximations (Abdullah, 2004). The programme had to estimate numbers of patients by site and then allocate appropriate budgets for drugs and labs, counsellors, nutrition, community and psychosocial support. Though in 2003 drug supply in ART-prescribing clinics was still patchy, the programme's parallel-systems approach to drug ordering, distribution and monitoring, had by the end of 2004 regulated supply. The programme also quickly mobilised Global Fund resources that became available from 2003; rapidly recruited and trained staff, for instance nurses and counsellors with ART-specific knowledge; and continually expanded their resource drive. Again, results were not immediate; in 2003-4 doctors dealing with ART in then-operational clinics were overwhelmed with patients and staffing levels are still hard to maintain. The programme also quickly constructed appropriate infrastructure, including building and expanding clinics, starting with initiator sites which were receiving the most referrals. Finally, to work well, the scaleup had rapidly to establish consensus with all 'stakeholders' or 75 
partners: patients, local communities, community-based organisations, HIV activists, interested national and international NGOs, and medical professionals at every level. From the beginning of the scaleup, resources were devoted to managing these partnerships so they could have rapid outcomes (Abdullah, 2006). One cannot scale up quickly, alone.

The detail, breadth, and speed of the scaleup's administrative technology constituted a micropolitics of the epidemic. It set up participants in the scaleup - patients and staff - as citizens functioning within the HIV epidemic: as HIV citizens with specific means of ensuring access to and effectiveness of treatment. However, some of this technology's elements, for instance the strong collaborations which guaranteed its speed, were also components of other key technologies in the scaleup.

\section{Partnership technologies}

Technologies of partnership were central to scaleup. 'Partnership' is a problematic matter, rarely as easy to establish or as equal as it proclaims. It is often invoked in HIV and development discourse, where commitment to it can be a condition of receiving funding (Heywood, 2004), but ignored or exploited in practice. Campbell's chapter provides many southern African examples of partnership discourse without practice. In other South African provinces it has been questionably successful in supporting scaleup, particularly early on (Beresford, 2004) The Western Cape scaleup also generated examples of the 76 
difficulties of national government, local government and civil society partnerships. However, it demonstrated that is possible to build associations of different and differently powerful 'stakeholders' in limited, contingent partnership working for specific goals around HIV treatment. In the Western Cape, such associations were essential for operational reasons, to deliver the medical and 'psychosocial' aspects of HIV treatment within resource-constrained circumstances, as well as ideologically, to promote a "positive spiral... where all parties were working together to do their best" in a programme seen to be "innovative, responsive and inclusive" (Abdullah, 2004: 258). Such associations construct another important level of citizenship in the HIV epidemic, building that citizenship's relationships and identities as well as its effectiveness.

The Western Cape already had high levels of HIV 'partnership'-derived cultural and social 'capital' - HIV knowledge and social associations - that enabled ART scaleup partnerships. For instance, PMTCT knowledge and practices encouraged ART literacy and enrolment from the start of scaleup. With only $33 \%$ of pregnant HIV positive women enrolled in such programmes worldwide, largely because of low antenatal clinic attendance (WHO, 2008), many countries cannot draw on such preexisting sociocultural capital. Some other South African provinces also have much lower antenatal HIV testing rates (Republic of South Africa, 2008). Scaleup was further enabled by province expertise derived from earlier ART trial and demonstration projects, and related collaborations between clinicians, researchers, local health officials, and international and national NGOs and CBOs. Unlike programmes in many other high-prevalence epidemics, the 77 
Western Cape scaleup could cite such existing effective partnerships when making funding applications: a considerable strength.

However, scaleup could not rely on preexisting partnerships to deal with the numbers requiring treatment across the whole province. The Department of Health had to create a generalised technology of partnership across all levels and sites of medical engagement. The scaleup devolves ART, often considered too complex and resource-intensive for primary health care environments, hence viewed as draining resources from and devaluing them, to precisely these environments, which are involved, too, in the programme's planning and monitoring. The scaleup's universal provision also lets primary-sector medical professionals address HIV much more effectively than before. Pre-scaleup, they were often reported as stigmatising, unhelpful and fatalistic (Squire, 2007). These reactions might be attributable partly to lack of treatment education (Beresford, 2004); partly to the 'deskilling,' frustrating and depressing effects of being unable to access proven effective treatment for fatally ill patients. In 2002, a doctor was fired from his government job for allowing prophylactic ART prescription to raped women. By contrast, the medical alliances promoted by the Western Cape scaleup support highly motivating partnerships in cutting-edge HIV treatment and care.

Partnership also extends to new professional groups. Pharmacists are specifically addressed as active scaleup partners (Naimak, 2006). 'Lay' HIV counsellors, mostly with no prior medical or psychological expertise, are trained to support people on ART at a 78 
maximum ratio of 1: 30, either visiting patients at home, giving onsite one-to-one counselling, or facilitating onsite groups - much as counsellors work with support groups on PMTCT programmes. Treatment expansion functioned for existing lay HIV counsellors, as for medical professionals, as a powerful incentive, turning their previous role of dispensing comfort and nutritional advice into one of providing effective medical referrals, alongside information and socioemotional support for 'living positively'. The partnership between lay counselling and the scaleup, building up a new, salaried profession of considerable size, has involved some economically-motivated compromises. Status differences between lay counsellors and nurses remain controversial, with the former paid by private companies tendering to the province's Department of Health, and therefore lacking health department benefits: holiday and sickness pay, unemployment insurance. This differential promotes turnover, constrained however by unemployment rates of over $50 \%$ in the townships, informal settlements and rural areas where most counsellors live. As in this case, partnerships are never relations between exact equals. They involve negotiation towards contingent, pragmatic consensuses, often hard-won, on specific issues at particular times.

The scaleup encourages but does not mandate partnership between medical facilities and local NGOs and CBOs. It asks them to collaborate in deciding and delivering support mechanisms. Some sites initially even made joint clinican-NGO or CBO decisions about which patients to admit to the first stages of rollout. The chosen method of education collective or individual - and adherence support - onsite or in the community, one-to-one 79 
or in a group, counsellor-led or facilitated by family and friends - appears not to affect outcomes significantly. However, collaboratively agreed-on provision seems important, given less favourable outcomes in other settings that provide support less systematically, for instance, through GP practice (Abdullah, 2004; Infectious Disease Epidemiology Unit/Department of Health, 2006). In addition, the province's failure to exceed two-thirds provision may relate partly to NGOs' continuing struggles to deliver the education and support they aim for.

Involvement in scaleup gave NGOs and CBOs, too, new impetus. For example, some CBOs providing homecare were able to go beyond palliative care for the first time. In this high-prevalence epidemic, almost all CBOs' and NGOs' remit now includes HIV, precipitating multiple partnership possibilities. However, non-HIV-related NGOs and CBOs may be excluded from the new resources that scaleup brings, and external funders' requirement that applicants prioritise HIV can skew their work. For instance, Western funders frequently ask proposals on child poverty and abuse, and gender-based violence, to foreground HIV. The Western Cape provincial government has addressed this issue by expanding work in these areas in addition to its HIV programmes.

The scaleup's commitment to partnership also means that the programme aims to build the provincial health system generally, alongside HIV care. Many health professionals are themselves HIV positive, so health services gain directly from HIV treatment. More generally, full scaleup is impossible in poorly-serviced areas and at primary healthcare 80 
level, without wholesale health system improvements. HIV's high demands on health services throughout subsaharan Africa have led to the mainstreaming of this double-track approach. Its implementation is not entirely successful. The Western Cape's failure to exceed two-thirds ART provision seems partly determined by continuing local health system deficits. Recent increases in patients lost to followup (Boulle et al., 2008) may indicate a system reaching capacity.

Partnership technologies can also offer an important alternative to the dichotomisation of HIV treatment and prevention. Treatment is often criticised as a diversion from prevention, supplanting it in policy, obviating considerations of prevention in HIV activism and in people's everyday lives (Davis, Mykhalovskiy, this volume), and abrogating scarce resources in the developing world. Though UNAIDS emphasises the necessary synergy of the two, HIV treatment is still often seen as creating divisions within health systems and stripping resources from prevention, which is associated less with scientifically-validated, prestigious, drug-driven and resource-intensive technologies, and more with behavioural technologies. The Western Cape's 'partnership' technology however means that scaleup is delivered alongside treatment literacy, prevention resources such as condoms, support for safe sex negotiation particularly for women, and general HIV education. This partnership is seeded by the educative effects of PMTCT programmes, particularly since these programmes reach almost all reproductive-age clinic-attending women. A related partnership, between scaleup and testing, has both prevention and treatment implications. As in other epidemics, testing became justifiable 81 
once treatment was available. On the back of universal PMTCT and the ART rollout, antenatal testing rates have risen to $94.8 \%$ (Draper et al., 2007).(I still need general adult testing rate)

Declining HIV incidence and rising HIV awareness among younger people; and rising age of sexual debut especially among young women (Flisher et al., 2006) - with figures better than in other South African provinces - suggest the effectiveness of the Western Cape scaleup's technology of treatment and prevention 'partnership'. While the province's early comprehensive treatment programme marks it out, that programme seems to work alongside its integrated address to prevention, to constitute an important, social level of active HIV citizenship in people's sexual talk and actions.

Campbell vividly describes the difficulties of building partnerships, even within wellresourced and committed HIV prevention and education programme. Often, 'partnership' operates largely at the level of discourse. The Western Cape programme does not however rely on discourse or voluntaristic practice, but devotes considerable resources to fostering and managing partnerships at every level. In some situations, Campbell describes how HIV is not a personal priority 'owned' by all stakeholders, and how partners are separated by prohibitive geographical and social distances. In the Western Cape scaleup, the recognition of strong common interests between partners was promoted from the start through a concurrent public education programme, and peer education in schools, constructing the province's high levels of HIV cultural capital. Partnership is 82 
also fostered by the programme's decentred processes, carried out by primary healthcare facilities, nurses, counsellors and NGOs clustered together within highly-affected neighbourhoods: everyone is close to the programme. Finally, perhaps most importantly, the promotion of treatment with education and prevention by the provincial health department, radically encourages partnership. HIV technologies that do not or cannot address the condition first as one that needs medical treatment, undermine their rationale by ignoring their own medical definition of their object, however much they are able to address other aspects of the condition.

The partnership-dependent delivery of ART, related prevention resources, and education for both treatment and prevention works horizontally and vertically, to develop social and cultural 'capital' (Campbell, 2003) within and across differently powerful groups: medical professionals; local politicians and officials; NGOs; CBOs; and community members who are patients, clients, service users and activists. These partnership-derived biosocialities of the epidemic are also part of a more broadly and actively articulated HIV citizenship, operating within and between these groups. For instance, drawing on ART programme partnerships, the Western Cape has supported campaigns against genderbased violence, a phenomenon linked to the epidemic in many ways (Jewkes, 2009). In these campaigns, HIV citizenship works both vertically, in partnerships between HIVrelated CBOs, the health department, and international donors; and horizontally, in partnerships between HIV positive women and men, and between people of different HIV statuses with common concerns about gendered violence and abuse. 
Partnership technologies can only go so far. HIV programme ownership is not, as Campbell notes, spontaneously shared; there is always a struggle. Building bridging social capital between individuals and organisations with differential access to resources, depends on addressing this discrepancy. The Western Cape scaleup has achieved an effective partnership technology that built HIV citizenship, not just through the partnership technology itself, but also through its commitment to a specific technology of HIV treatment citizenship, that addressed power relations directly. Treatment citizenship is a constitutive element of all HIV citizenship in the era of treatment possibility. In the Western Cape scaleup, however, the formations of representation and action that make up HIV treatment citizenship have a particular role.

\section{HIV treatment citizenship}

The Western Cape scaleup deploys a technology of HIV treatment citizenship that is less explicitly planned than the other technologies and harder to measure or record, but that is frequently remarked on in commentaries on the programme (Robins, 2008) This treatment citizenship technology is characterised by people's self-representation and action as members of HIV collectivities. The collectivities present as political, in the sense that they contest the power relations of HIV treatment, through education, social dialogue, and activism.

Some treatment citizenship technology is easily apparent as such. For instance, the 84 
Khayelitsha ART demonstration project assessed applicants partly on the basis of their involvement with local HIV CBOs, at this point largely oriented towards treatment activism. Active treatment citizenship was thus a treatment criterion. The scaleup's implementation partnerships with NGOs and CBOs quickly also became partnerships with campaigners and activists. More generally, some patients, relatives and friends engaged strongly with medical and political institutions from the start, as in other epidemics (Epstein, 1996), demanding first treatment for opportunistic infections, then PTMCT, then ART, then specific medications not available within local or national protocols or supply chains. Many such campaigns appeared most strongly and first in this province, though the treatment-activist engagement of people throughout South Africa, especially via TAC, has been strong (Naimak, 2006). Robins (2008) describes this activism as a form of health citizenship, pursuing the rights guaranteed within the famously progressive South African constitution, which upholds the principles of Batho Pele - People First - and a 'better life for all.' He points to the strategic use of rights discourse within TAC which managed to articulate demands for ART in a national context of 'AIDS denialism', and in a language shared with the international governance discourse of the WHO and UN (see also Mbali, 2005).

However, across the Western Cape scaleup only some patients and fewer doctors participated in campaigning assertions of treatment citizenship. Activism is just the most visible face of treatment citizenship technology; the specificities of the condition necessitate other forms as well. HIV's stigmatisation and perceived transgressiveness 85 
consistently constrain activism. HIV's treatment normalisation may also divert activism, as in developed-world countries (Davis, Flowers, Mykolovskiy, this volume). However, the difficulties of living with high-prevalence HIV, low-resources and variable ART access, as in South Africa, differently limit activist commitment. The other kinds of treatment citizenship technology that play a part in the Western Cape's scaleup, are HIV education, and HIV sociality.

Treatment education, driven by the possibility of treatment even before treatment was available, has been integral to the scaleup's treatment citizenship technology. The province expanded ART education in parallel with scaleup, and some treatment literacy is required of all patients starting ART. Even in 2001, well before national education programmes on the issue, let alone ART or indeed other treatment availability, there was some province-wide education on treatment, as well as testing, healthy living, and prevention - by NGOs, CBOs, popular media, and the province itself. The province's rollout of PMTCT programmes also educated people who, seeing the healthy babies of HIV positive women, started to demand the drugs for themselves. ART literacy in the Western Cape at the beginning of scaleup seemed relatively high. Even in 2001, HIVinfected people in the main periurban area had relatively good levels of knowledge of ART and other drugs (Squire, 2007).

Much treatment education was informally pursued, not formally delivered. Given government criticism of ART as exploitative and toxic, knowledge of it had to be wrested 86 
from competing sources of information. Patients' unexpectedly high levels of adherence often seems related to this self-educated engagement. Anecdotally, many clinicians report that people taking ART know the names of their drugs, alternatives available, and possible sideeffects, to a much greater extent than patients living with other chronic conditions such as diabetes and heart disease. Actively pursed, contested education thus seems a powerful aspect of the Western Cape's treatment citizenship, as it has been in elsewhere. As is sometimes argued of Uganda (Epstein, 2006), HIV began stabilising when many within the epidemic became active, educated 'HIV citizens.' In the Western Cape, this happened first in the treatment, rather than prevention, arena.

Educated treatment engagement has spread outward from the Western Cape, particularly to family members living elsewhere. For instance, in the group of those 'lost to (treatment) followup' in the scaleup, a term which might suggest uncommitted or disorganised patients, many show high treatment commitment, and treatment planning. Some pregnant HIV positive women, for example, made their way to the Western Cape from other provinces with great difficulty, since they had no cash income for transport, to access its PMTCT programme, Other women and men, similarly cash-poor, came to the province to stay with family members and pursue their own treatment. Later, as treatment expanded for instance in the Eastern Cape, and as PMTCT babies were doing well, some patients returned home and thus were 'lost.' Currently, the scaleup's success means many patients feel free to move between medical facilities - moves which make care retention 87 
statistics in a paper-based system, difficult to keep.

If treatment education was informal and contested, how did it work so well? The key route reported by Squire's (2007) informants, suggested by Campbell and colleagues (2007) in their accounts of developing 'HIV competence' in South African rural settings, and also indicated by accounts of the effectiveness of support and counselling groups (Hutchinson and Mahlalela, 2006; Flowers et al., 2006) involves not just obtaining knowledge, but also safe and open HIV sociality. This route recalls Rabinow's (1996) formulation of 'biosocial' collectivities organised around contested biological subjectivities. There is a possible, though not inevitable, association between such sociality - which also helps constitute, for instance, the 'partnership' technology, described above - and the broader identifications and actions of treatment citizenship. Campbell and colleagues (2007) also specify that HIV competence involves owning the virus socially as 'our problem,' through the horizontal social-capital linkages described earlier as part of politicised partnership; and social effectivity. This account comes close to a Freirian programme for generating social change through collective critical dialogue (Freire, 1973). Western Cape treatment protocols, from the demonstration projects on to the scaleup, clearly embedded citizenly ART understanding and effectivity within sociality. They asked for NGOs, CBOs, and family and friends' involvement. Many required the participation of a familial or friend 'treatment assistant'. Building on the Western Cape demonstration projects, WHO ART scaleup guidelines also emphasise community and family support. 
In ART scaleup discourse, therefore, people taking treatment, and their treatment assistants, are positioned as effective treatment citizens alongside medical professionals, forming contingent alliances with medical discourse, negotiating with it, disseminating this negotiated treatment knowledge socially, and negotiating with it further in the process (Robins, 2008). This engagement is borrowed for public discourse, as it was in developing-world epidemics, from its earlier activist and community incarnations (Davis et al., 2006; Epstein, 1996). In the Western Cape, this discourse was at least partly effective in practice. The drive towards treatment literacy in advance of scaleup set up an important HIV sociality of people throughout the province, discussing ART in families and friendship networks as well as CBOs and NGOs. This sociality appeared in the early2000s concern of many people living around the demonstration and initial scaleup sites to 'speak out' about their status, and how one can live with and be treated for HIV as an illness, not as a sign of social or spiritual transgression (Squire, 2007). The sociality of scaleup itself, institutionalised in decentred structure of local clinics' implemention strategies, allowed patients' groups and CBOs input into guidelines for starting and supporting treatment. These discussions migrated outward into broader family, friendship and community socialities. Such a socialised treatment citizenship technology seems now to extend across the province, and may be another factor contributing to the Western Cape's high HIV test rates, and the rise in sexual debut age in the province (Flisher et al., 2006) - something often said to be associated with the plateauing of other highprevalence epidemics (Epstein, 2006). 
Treatment citizenship could be seen as a kind of 'capacity building.' Campbell is rightly sceptical about this process, describing it as fatally self-undermining. Generally, efforts at building treatment citizenship technologies, or Campbell's broader category of HIV competence, try to correct resource inequities by transferring resources defined by those that have them, who also decide how they shall be transferred and when they have been successfully moved over. Such programmes' understanding of power differences is undercut by their re-performance of these differences precisely while combatting them. The contested nature of politics (Mouffe, 2005) is acknowledged in analysis, erased in implementation. In the case of the Western Cape scaleup however, the technology of treatment citizenship was to a large extent defined, appropriated and developed by the people requiring it.

Treatment citizenship is not equivalent to HIV citizenship in general, but its technology may build that broader formation. We have seen how the province's prevalent forms of treatment citizenship seem associated with high levels of HIV testing, and changes in sexual relationship patterns. In addition, Western Cape treatment citizenship generated, and continues to support, jointly-developed campaigns by medical professionals, NGOs and CBOs, for cheap access to key license-protected drugs; but also NGOs' and CBOs' development of support services, for instance around gender violence. CBOs' involvement in treatment education has led to stronger prevention and education programmes, an integration of great concern to people of all statuses in South Africa. 
With the help of a supportive doctor, Western Cape women enrolled in PMTCT programmes began educating other pregnant positive women, a commitment now formalised in 'Mothers2mothers2B' groups which have spread across South Africa and other southern African countries (http://www.m2m.org/). ART support groups, concentrated at the beginning of treatment, have spun off income generation projects. People 'speaking out' about HIV as a treatable, liveable-with illness, promote dialogue not just about HIV status and treatment, but also about HIV's nature, prevention, and implications for the nation and the future (Daniel and Squire, 2009).

Even in talking of their treatment 'rights' as citizens, people living with HIV in the Western Cape assert 'rights' in ways that are not restricted to treatment or health citizenship exclusively, but that do not either become generalised assertions of 'human' rights (Robins, 2008). Between 2001 and 2004, for example, Squire's interviewees articulated 'rights' particularly and transitively in relation to HIV's impact in different fields, specifying entitlements to goods in health, social, employment and education fields. HIV positive people demanded treatment, but also food for their children once PTMCT programmes - which provide infant formula - had been completed, and food for themselves to promote the success of ART (an issue of which scaleup programme directors were well aware -see Abdullah, 2004). They asked for funeral grants for family members who died of HIV, and for flexible disability grants, since even with ART, continuous paid work can be problematic for HIV positive people, assuming they can get such work. They wanted training that would enable them to work in areas suitable for 91 
chronically ill people. This specificity about who has rights, and to what, clarifies convergences and distinctions between HIV positive and other citizens, that is, their equivalent identities (Mouffe, 2005), while also defining contemporary HIV citizenship in ways that go beyond treatment citizenship. The technology of HIV citizenship built up through the rollout can then be summarised as a pragmatic citizenship, equivalent with but not identical to the citizenship of the non-HIV affected, that lays out commonalities with other citizens, while still marking the important particularities of the condition.

In addition, people living with or alongside the demonstration projects and scaleup have developed HIV citizenship as a moral formation. They describe how to live well as HIVpositive citizens in ways that speak back to HIV's social and religious pathologisation, and that closely match broader South African understandings of good conduct and appropriate ways of living. They adumbrate a pragmatic 'somatic ethics' (Rose, 2007: 252) involving care of the self through cleanliness, diet and exercise; care of others children, partners and neighbours; cooking and cleaning; paid work when possible; and a social commitment to speaking and acting truthfully and ethically - in this case, about HIV. These formulations of care of self and others within HIV citizenship technology relate to the principle of $u b u n t u$, the humanity inherent in living through and for others, mentioned by some of Squire's (2007) interviewees and a frequent point of cultural and political reference in South Africa. Interviewees emphasised that a person living with HIV was 'still' a person and not an animal, and must be socially recognised as such, despite their specific characteristics and requirements. Such formulations embed 92 
politically equivalent HIV citizenship in ethical but still pragmatic considerations about how to live well in specific contexts, including that of HIV.

We have suggested that the Western Cape ART scaleup can be analysed as working through a triad of administrative, partnership and citizenship technologies, built up from near-zero in some places and cases, to high and largely self-sustaining levels. The scaleup technologies were not necessarily or exactly connected with people's development of a wider HIV citizenship; they had some independent fields of action. However, it is clear that they contributed to the constitution of this broader HIV citizenship within the province. These technologies can be worked with in other contexts, but crucial to their effectiveness has been their recognition of factors that must be addressed locally. Such particularity, instantiated in the scale-up's commitment to neighbourhood-developed strategies, renders the technologies resistant to exact translation.

The technologies also present substantial problems of contemporary and future implementation, derived from their own heterogeneities and contradictions, as well as from those that appear in their relation with other, medical social and political technologies.

\section{The limits of scaleup technologies}

Throughout the scaleup, its technologies have encountered a number of resistances, some of which are likely to persist and strengthen. The scaleup has not made HIV citizens of 
the 20000 people estimated to be HIV positive and to need treatment, who are not accessing it. Partial explanations for this may lie, as mentioned earlier, in the limitations of the programme's administrative technology, particularly in health service resources reaching their limits. In addition to the general programme, the health department is now targeting the specific local problematics of HIV in relation to older men, schoolchildren, sex workers and truck drivers. The scaleup may also have encountered a geographic limit in reaching people who can access clinics by walking or by car; many rural settlements are not served by roads. As people live longer, the complications of longterm ART use become more common, more people progress to ART, increasing numbers move onto expensive second- and third-line drug regimes, and incidence remains high, problems will multiply. Men, who have little contact with South African health services, are consistently underrepresented in treatment at $30 \%$ of the total - though more women are HIV positive (Boulle et al., 2008). Women continue to face gendered stigmatisation and disclosure difficulties (Ratele and Shefer, 2002; Rohleder and Gibson, 2006). HIV's dramatic impact at diagnosis and its stigmatisation persists, in South Africa and globally (Flowers, this volume; Stevens and Hildebrandt, 2006). Acknowledging the condition, disclosing (Flowers, this volume) embarking on lifelong medication, and dealing with sideeffects and HIV's ongoing medical uncertainties (Davis, this volume; Olley et al., 2005) continue to be difficult. New prevention issues arise for those taking ARTs or simply having sex in the ART era, particularly for women who are now formulating their AIDS-era sexualities in new ways. Younger people particularly are becoming accustomed to, even bored with HIV, as this high-prevalence epidemic moves into a second decade of 94 
public awareness and action.

All these characteristics suggest the importance of 'psychosocial' factors to which, as mentioned earlier, medical, NGO and CBO partnership technology in the scaleup have not yet made full responses. Given the newness, high prevalence, particularity and fluidity of this epidemic, an expectation that neighbourhoods and communities could develop their own fully adequate and sustainable support mechanisms to cover all of these areas of the 'psychosocial' out of ART partnership technologies, would be overoptimistic. The 'psychosocial' itself may need redefinition within ART technologies (Wilbraham, this volume). Moreover, while the scaleup programme certainly acknowledges the multiple dimensions of what we have called 'treatment citizenship,' that citizenship's overtly political and educative elements have been privileged. Its more diffuse sociality is harder to describe, let alone encourage; and it is always under challenge. For though everyone in South Africa is in some way 'living with' HIV, the 'equivalence' between different citizens - between HIV positive women and men, the positive well and the symptomatic, the infected and the affected, parents and their children - is approximate, changing, and contested.

A further criticism addresses the scaleup's medical focus. Does this focus inevitably 'medicalise' HIV citizenship? Treatment-oriented responses to the pandemic are frequently accused of reducing people's relations with HIV to that of patients and research subjects'relations to disease and virus. This accusation also applies to recent treatment95 
oriented prevention discourse that, instead of focusing on personal and social action, promotes early (Granich et al., 2009) or prophylactic (Rosengarten, this volume) ART. Microbicides and circumcision, ART post-sexual assault, even condoms and clean needles, can also be conceptualised as medicalisations of prevention. Such criticisms often link to broader condemnations of subjects' and whole economies' cooption by pharma-capital, and of developing countries' surveillance by international NGOs such as the WHO. However, to equate treatment activism, at for instance the Western Cape neighbourhood or local government level, with international treatment capitalism and postcolonial regulation, seems patronisingly over-simplifying. There is, too, considerable heterogeneity within the biopolitics of both international NGOs and pharmacological companies, which are also not the least socially responsible or responsive corporate sector. South Africa is in addition, like many other subsaharan African countries, trying to expand its own 'small pharma' production of ART drugs, a development that, like developing countries' production of generics, complicates biocapital analysis.

The 'medicalisation' critique of treatment scaleup is most aptly countered in the Western Cape case by the programme's actualities. Even when the scaleup's non-medical partners developed medical expertise, they did not become medicalised citizens wholly coopted by western medical discourse and practice. Most people taking ART for instance also use traditional and complementary approaches they think appropriate, often in consultation with their doctors, as indeed happens across developing and developed-world HIV epidemics and in developing-world health care in general. While patients have high 
treatment literacy and commitment, they are not generally strongly identified with medical expertise. Their relations with their doctors tend to be relatively conventional partnerships, with patient and practitioner roles clearly separated. More importantly, the non-medical technologies that we have described were key to scaleup's successs. Administrative and partnership technologies were formulated and implemented with relative autonomy from the medical technologies of ART. Even treatment citizenship, the technology most focussed on medicine, configured health information in terms of activism and social dialogue, and had important associations with broader forms of HIV citizenship.

\section{Conclusion}

How will the Western Cape programme's scaleup technologies fare in future? The plan is to double enrolment yearly for the next five years, particularly focusing on underrepresented men. As more patients stay on therapy, more will move to expensive second-line drugs. Numbers of people requiring treatment will continue to rise well into the next decade and beyond, if numbers of new cases do not fall (Western Cape, 2006). The resourcing of such extensive treatment, even given generic provision and domestic manufacture, will be a growing concern. The psychological, social and political consequences for large fractions of the population living long-term with difficult medical treatment are hard to predict. Achmat and Simcock (2007) are optimistic about the ameliorative effects of longterm treatment combined with prevention, education and community mobilization - the wider HIV citizenship technologies discussed above. 
Draper and cowriters (2007) call for largescale and thoroughgoing initiatives that do not look qualitatively different from those currently operating. The citizenship, administrative and partnership strategies discussed here, may, despite their limitations, be able to address at least some of the future conditions of this epidemic, and perhaps of others.

\section{References}

Abdullah, F. (2004) 'The complexity of implementing antirretroviral therapy in the Western Cape province of South Africa', in M. Heyward (ed) From disaster to development? HIV and AIDS in Southern Africa, Development Update 5, 3, 245264.

Abdullah, F. (2006) 'Lessons from the field; ART scaleup in South Africa. XVIth International AIDS Conference, Toronto.

Abdullah, F., Bock, P., Osler, M. and Boulle, A. (2006) 'Clinical outcomes in ART scaleup, Western Cape Province of South Africa', XVIth Interational AIDS Conference, Toronto.

Achmat, Z and Simcock, J (2007) 'Combining prevention, treatment and care: lessons from South Africa', AIDS, 21, Suppl 4, S11-S20.

Beresford, B. (2004) 'Pioneering treatment access in a rural area of South Africa', in M. Heyward (ed) From disaster to development? HIV and AIDS in Southern Africa, Development Update, 5, 3, 277-292.

Boulle, A., Bock, P., Osler, M., Cohen, K., Channing, L., Hildebrand, K, Mothibi, E., 98 
Zweigenthal, V., Slingers, N., Cloete, K. and Abdullah, F. (2008)

'Antiretroviral therapy and early mortality in South Africa', WHO Bulletin 86. 678687.

Campbell, C. (2003) Letting them die? (Oxford: James Currey).

Campbell, C., Nair, Y, Maimane, S, and Sibiya, Z (2007) 'Building contexts that support effective community responses to HIV/AIDS', American Journal of Community Psychology, 39, 3-4, 347-363.

Chesney, M. and Smith, A. (1999) 'Critical delays in HIV testing and care: the potential role of stigma', American Behavioural Scientist, 42, 1162-1174.

Coetzee, D., Hildebrand, K., Boulle, A., Maartens, G., Louis, F., Labatala, V., Reuter, H., Ntwana, N. and Goemaere, E. (2004) 'Outcomes after two years of providing antiretroviral treatment in Khayelitsha, South Africa', AIDS, 18, 887-895.

Daniel, L. and Squire, C. (2009) 'Experiences of people living with HIV', in P. Rohleder, L. Swartz, S. Kalichman and L. Simbayi (eds) HIV/AIDS in South Africa 25 years on (New York: Springer).

Davis, M., Frankis, J. and Flowers, P. (2006). 'Uncertainty and technological horizon in qualitative interviews about HIV treatment', Health 10, 3, 323-344.

Draper, B., Pienaar, D., Parker, W. and Rehle, T (2006) 'Recommendations for policy in the Western Cape Province for the prevention of major infectious Diseases, including HIV/AIDS and tuberculosis. (Cape Town: Western Cape Department of Health)

Cape Town: Provincial Government of the Western Cape (2006). 'The Western Cape 99 
Antiretroviral Programme: Monitoring Report', http://web.uct.ac.za/depts/epi/artrollout/files/Artmonitoringreport_wc_062006.p

Df, 12 July 2008.

Epstein, H. (2006) The invisible cure (New York: Farrar, Straus and Giroux).

Epstein, S. (1996) Impure science: AIDS, activism and the politics of knowledge (Los Angeles, CA: University of California Press).

Flowers, P., Davis, M., Hart, G., Rosengarten, M., Frankis, J. and Imrie, J. (2006)

'Diagnosis and stigma and identity amongst HIV positive Black Africans living in the UK', Psychology and Health 21, 1, 109-122.

Foucault, M. (1980) History of sexuality volume 1 (London: Allen Lane).

Freire, P. (1973). Education for critical consciousness (New York: Continuum).

Granich, R., Gilks, C., Dye, C., De Cock, K. and Williams, B. (2009) 'Universal voluntary HIV testing with immediate antiretroviral therapy as a strategy for elimination of HIV transmission: a mathematical model', Lancet 373, 9657, 48-57.

Heywood, M. (2004) 'Editor's preface', in M. Heywood (ed) From disaster to development? HIV and AIDS in Southern Africa, Development Update 5, 3, 3-16.

Hutchinson, P. and Mahlalela, X. (2006) 'Utilisation of voluntary counselling and testing services in the Eastern Cape, South Africa', AIDS Care, 18, 5, 446-455.

Infectious Disease Epidemiology Unit UCT/Department of Health (2006) Models of care for antiretroviral service delivery. (Cape Town: Western Cape Department of Health).

Jackson, D., Chopra, M., Doherty, T., Colvin, M., Levin, J., Willumsen, J., Goga, A. and 100 
Moodley, P. for the Good Start Study Group (2007) 'Operational effectiveness and 36-week HIV-free survival in the South African programme to prevent mother-tochild transmission of HIV-1', AIDS 21, 509-516.

Jewkes, R (2009) 'HIV and women', in P. Rohleder, L. Swartz, S. Kalichman and L. Simbayi (eds) HIV/AIDS in South Africa 25 years on (New York: Springer).

Kim, J. (2006) 'Lessons from the field: overview', Toronto International AIDS Conference. http://www.kaisernetwork.org/health_cast/hcast_index.cfm?display=detail\&hc=180

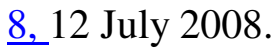

Mbali, M. (2005) 'The Treatment Action Campaign and the history of rights based patient-driven HIV/Aids activism in South Africa', Centre for Civil Society Research Report 29, 1-23.

Moodley, D., Moodley, J., Coovadia, H., Gray, G., McIntyre, J., Hofmyer, J., et al. (2003) 'A multi-center randomized controlled trial of nevirapine versus a combination of zidovudine and lamivudine to reduce intrapartum and early postpartum mother-tochild transmission of human immunodeficiency virus type 1', Journal of Infectious Diseases 187, 725-735. Mouffe, C. (2005) The return of the political (London: Verso)

Naimak, T. (2006) 'Antiretroviral treatment in the Western Cape', CSSR Working Paper 161, http:///www.cssr.ac.za/index/htm, 12 July 2008.

Olley, B., Zeier, M., Seedat, S. and Stein, D. (2005) 'Post-traumatic stress disorder 101 
among recently diagnosed patients with HIV/AIDS in South Africa', AIDS Care 17, $5,550-557$.

Rabinow, P (1996) Essays on the anthropology of reason (Princeton: Princeton University Press).

Ratele, K. and Shefer, T. (2002) 'Stigma in the social construction of sexually transmitted diseases', in D. Hook and G. Eagle (eds) Psychopathology and social prejudice (Cape Town: University of Cape Town Press).

Republic of South Africa (2008) 'Progress report on the declaration of commitment on HIV/AIDS', http://data.unaids.org/pub/Report/2008/south_africa_2008_country_progress_report _en.pdf, 12 July 2008.

Robins, S. (2008) From revolution to rights in South Africa, (Durban: UKZN Press). Rofes, E. (1998) Dry bones breathe. (New York: Harrington Park Press).

Rohleder, P. and Gibson, K. (2006). “We are not fresh”: HIV-positive women talk of their experience of living with their spoiled identity', South African Journal of Psychology, 36, 1, 25-44.

Rose, N. (2007) The politics of life itself (Princeton, New Jersey: Princeton University Press).

Skogmar, S., Shkaeley, D., Lam, M., Daniell, J., Andersson, R., Tshandu, N., Odón, A., Roberts, S. and Venter, F. (2006) 'Effects of antiretroviral treatment and counselling on disclosure of HIV serostatus in Johannesburg, South Africa', AIDS Care 18, 7, 725-730. 
Stevens P. and Hildebrandt, E. (2006) 'Life changing words: women's responses to being diagnosed with HIV infection', Advances in Nursing Science 29, 3, 207-221.

Sunder, K, (2006) Biocapital (Durham, North Carolina: Duke University Press).

UNAIDS (2008) 'AIDS epidemic update', http://www.unaids.org/en/

HIV_data/epi2008/default.asp, 4 March 2009.

Uys, P. (2008) 'Western Cape Health Budget 2008/9', http://www.capegateway.gov.za/other/2008/5/wc_health_budget_speech_2008.pdf, 2 May 2009

Western Cape Department of Health (2006) 'The Western Cape antiretroviral programme monitoring report', http://www.capegateway.gov.za/eng/pubs/reports_research/W/157844, 12 July 2008

Wolfe, W., Weiser, S., Leiter, K., Steward, W., Percy-de Korte, F., Phaladze, N., Iacopino, V. and Heisler, M. (2008) 'The impact of universal access to antiretroviral therapy on HIV stigma in Botswana, American Journal of Public Health, 98, 10, 1865-1871.

World Health Organisation (2003) Antiretroviral treatment in primary health care: experience of the Khayelitsha programme in South Africa (Geneva: World Health Organisation) http://www.who.int/hiv/pub/prev_care/en/South_Africa_E.pdf, 4 March 2009.

World Health Organisation (2006) Progress on global access to HIV antiretroviral therapy (Geneva: World Health Organisation) 
http://www.who.int/hiv/progressreport2006_en.pdf, 12 July 2008.

World Health Organisation (2007) Towards universal access: scaling up priority

HIV/AIDS interventions in the health sector: progress report (Geneva: World

Health Organisation)

http://www.who.int/hiv/mediacentre/universal_access_progress_report_en.pdf, 4

March 2009. 